\title{
Spatial-Temporal Variations of Turbidity and Ocean Current Velocity of the Ariake Sea Area, Kyushu, Japan Through Regression Analysis with Remote Sensing Satellite Data
}

\author{
Kohei Arai \\ Graduate School of Science and Engineering \\ Saga University \\ Saga City, Japan
}

\author{
Yuichi Sarusawa \\ Graduate School of Science and Engineering \\ Saga University \\ Saga City, Japan
}

\begin{abstract}
Regression analysis based method for turbidity and ocean current velocity estimation with remote sensing satellite data is proposed. Through regressive analysis with MODIS data and measured data of turbidity and ocean current velocity, regressive equation which allows estimation of turbidity and ocean current velocity is obtained. With the regressive equation as well as long term MODIS data, turbidity and ocean current velocity trends in Ariake Sea area are clarified. It is also confirmed that the negative correlation between ocean current velocity and turbidity.
\end{abstract}

Keywords-turbidity; ocean current; remote sensing satellite; regressive analysis

\section{INTRODUCTION}

There are strong scientific demands on estimation of environmental situations including water quality of the ocean. Primary productivity, ocean disaster such as red tide, ocean pollution and ocean water quality monitoring is getting much important in conjunction of global environmental issues. This paper deals with water quality, in particular, Suspended Solid: SS related turbidity and ocean current. There are some proposed methods with remote sensing satellite data for SS estimation while not so many method is proposed for ocean current velocity estimation. The method proposed here is based on regressive analysis. Regressive analysis based SS estimation method is conventional method. Also ocean current velocity estimation method proposed here is based regressive analysis.

Recently, the Ariake Sea environment is getting worth. Red tide occurrence is getting much frequent together with scale of the red tide. There are some evidences which indicate increasing of the Ariake Sea transparency. In the meantime, ocean current velocity of the Ariake Sea is decreasing. Most of these evidences are based on the measured data with research vessels. Namely, these data are obtained along with research vessels' routes. On the other hands, remote sensing satellite data derived turbidity, ocean current velocity is essentially acquired with area based measurements. Therefore, it is possible to cover almost whole Ariake Sea area at once. This is the greatest advantage of the satellite based measurements. Furthermore, it is also possible to monitor these situations repeatedly for a long time period by using remote sensing satellite data. Thus seasonal changes and long term trend of turbidity or transparency and ocean current velocity of the Ariake Sea can be clarified.

The following section describes the method for estimation of turbidity and ocean current velocity followed by some experimental data. Then conclusion is described with some discussions.

\section{REGRESSION BASED METHODS FOR TURBIDITY AND OCEAN CURRENT VELOCITY ESTIMATIONS}

\section{A. Regression Based Method}

Regression based approach is, generally, expressed as follows,

$$
\operatorname{Turb}^{\prime}=\alpha *\left[L_{w}(667)\right]_{N}+\beta
$$

where Turb' denotes turbidity while $\mathrm{L}_{\mathrm{w}}(667)_{\mathrm{N}}$ denotes water leaving radiance at $667 \mathrm{~nm}$ of observation center wavelength of the spectral band. Atmospheric contribution is dominant for the acquired water leaving radiance so that the atmospheric corrected $\mathrm{L}_{\mathrm{w}}(667)_{\mathrm{N}}$ is used for the experiments. There are MODIS Ocean Products including atmospheric corrected water leaving radiance which are provided by NASA/GSFC. On the other hands, $\alpha$ and $\beta$ are regressive coefficients. These coefficients are obtained through regressive analysis which minimizing the following,

$$
E^{2}=\sum\left(y_{i}-\hat{y}_{i}\right)^{2}=\sum\left(y_{i}-a-b x_{i}\right)^{2}
$$

where $\mathrm{a}$ and $\mathrm{b}$ are regressive coefficients $\mathrm{x}$ and $\mathrm{y}$ are $\mathrm{L}_{\mathrm{w}}(667)_{\mathrm{N}}$ and turbidity, respectively. If the following equation can be assumed,

$$
\frac{\partial E}{\partial b}=\frac{\partial E}{\partial a}=0
$$

then the coefficients are determined as follows,

$$
b=\frac{\sum\left(x_{i}-\bar{x}\right)\left(y_{i}-\bar{y}\right)}{\sum\left(x_{i}-\bar{x}\right)^{2}}, a=\bar{y}-b \bar{x}
$$


where $\bar{x}, \bar{y}$ denote means of $\mathrm{L}_{\mathrm{w}}(667)_{\mathrm{N}}$ and turbidity, respectively.

\section{B. Remote Sensing Satellite Data Used}

As aforementioned, MODIS onboard Terra and Aqua satellites is the most appropriate mission instrument. The MODIS swath width is wide enough for the Ariake Sea together with Instantaneous Field of View: IFOV. Also MODIS has 36 spectral channels which are suitable for estimation of turbidity and ocean current velocity. Table 1 shows the spectral channels of MODIS.

TABLE I. SPECTRAL CHANNELS OF MODIS

\begin{tabular}{|c|c|c|}
\hline Primary Use & Band & Bandwidth ${ }^{1}$ \\
\hline \multirow{2}{*}{$\begin{array}{l}\text { Land/Cloud/Aerosols } \\
\text { Boundaries }\end{array}$} & 1 & $620-670$ \\
\hline & 2 & $841-876$ \\
\hline \multirow{5}{*}{$\begin{array}{l}\text { Land/Cloud/Aerosols } \\
\text { Properties }\end{array}$} & 3 & $459-479$ \\
\hline & 4 & $545-565$ \\
\hline & 5 & $1230-1250$ \\
\hline & 6 & $1628-1652$ \\
\hline & 7 & $2105 \cdot 2155$ \\
\hline \multirow{9}{*}{$\begin{array}{l}\text { Ocean Colorl } \\
\text { Phytoplankton/ } \\
\text { Biogeochemistry }\end{array}$} & 8 & $405-420$ \\
\hline & 9 & $438-448$ \\
\hline & 10 & $483-493$ \\
\hline & 11 & $526-536$ \\
\hline & 12 & $546-556$ \\
\hline & 13 & $662-672$ \\
\hline & 14 & $673-683$ \\
\hline & 15 & $743-753$ \\
\hline & 16 & $862-877$ \\
\hline \multirow{3}{*}{$\begin{array}{l}\text { Atmospheric } \\
\text { Water Vapor }\end{array}$} & 17 & $890-920$ \\
\hline & 18 & $931-941$ \\
\hline & 19 & $915-965$ \\
\hline
\end{tabular}

IFOV are different by spectral channels, $250 \mathrm{~m}$ for channels 1 and 2, 500m for channels 3 to 7 and $1000 \mathrm{~m}$ for the rest of channels. Therefore, all the ocean products are defined as $1000 \mathrm{~m}$ IFOV of products. On the other hands, the size of the Ariake Sea is $30 \mathrm{~km}$ by $100 \mathrm{~km}$ so that $1 \mathrm{~km}$ IFOV of ocean products would be enough.

\section{Trith Data Used}

Match-up data between MODIS and truth data of turbidity which are obtained at the Saga University Observation Tower which is situated at the (33.1001147 North, 130.273915 East) are collected for three months during from June to August 2010. Figure 1 shows the Google map of the Ariake Sea which is situated in Kyushu, Japan. Figure 1 also shows the location of Saga University Observation Tower. Turbidity is measured with electro-magnetic wave scattering radiance at the sea surface at the observation tower. Through a comparison with Holmagen standard liquid, the measured turbidity is calibrated. The unit of turbidity is FTU.
Table 2 shows the list of the data of the dates of turbidity measurements (Turb), the water leaving radiance in unit of $\mathrm{mW} / \mathrm{cm}^{2} / \mathrm{str} / \mathrm{um}$ at the four different channels which alhas the center wavelength, 412, 443, 531, and $667 \mathrm{~nm}$.

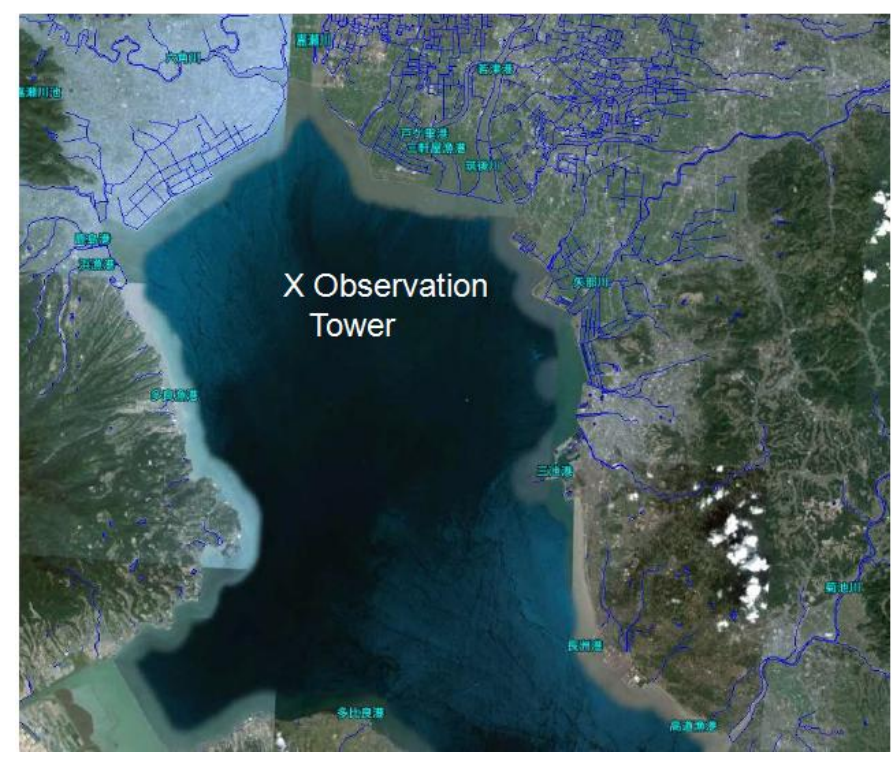

Fig.1. Google map of the Ariake Sea and the location of Saga University Observation Tower

TABLE II. MATCH-UP DATA BETWEEN MODIS AND TRUTH DATA OBTANIND AT THE SAGA UNIVERSITY TOWER FOR JUST THREE MONTHS FROM JUNE TO AUGUST 2010.

\begin{tabular}{|c||c|c|c|c|c|}
\hline Date & 412 & 443 & 531 & 667 & Turb \\
\hline $2010 / 06 / 0211: 00$ & 0.5549 & 0.758 & 1.6932 & 0.5243 & 3.2 \\
\hline $2010 / 06 / 0312: 00$ & 0.697 & 0.7029 & 1.5953 & 0.5707 & 3 \\
\hline $2010 / 06 / 0911: 00$ & 0.8175 & 1.0853 & 2.0067 & 0.7259 & 7.7 \\
\hline $2010 / 07 / 2011: 00$ & 0.2687 & 0.3801 & 1.3053 & 0.5695 & 7 \\
\hline $2010 / 07 / 2014: 00$ & 0.3707 & 0.3684 & 0.7593 & 0.2527 & 4.1 \\
\hline $2010 / 07 / 2113: 00$ & 0.4012 & 0.2148 & 0.6054 & 0.1987 & 4.9 \\
\hline $2010 / 07 / 2213: 00$ & 0.7987 & 1.0449 & 1.984 & 0.9338 & 4.5 \\
\hline $2010 / 07 / 2313: 00$ & 1.0671 & 1.3122 & 2.3904 & 1.4277 & 10.3 \\
\hline $2010 / 8 / 611: 35$ & 0.7874 & 0.5541 & 1.2454 & 0.5381 & 2.7 \\
\hline $2010 / 8 / 613: 10$ & 0.5967 & 0.5353 & 1.1487 & 0.4942 & 3.1 \\
\hline $2010 / 8 / 1813: 35$ & 0.5477 & 0.513 & 1.0888 & 0.453 & 2.5 \\
\hline $2010 / 8 / 1911: 00$ & 0.6398 & 0.727 & 1.7675 & 0.8588 & 3.6 \\
\hline $2010 / 8 / 2110: 50$ & 0.2006 & 0.2884 & 0.936 & 0.2832 & 2.4 \\
\hline $2010 / 8 / 2114: 00$ & 0.3947 & 0.5356 & 0.9892 & 0.2442 & 2.4 \\
\hline $2010 / 8 / 2213: 10$ & 0.8374 & 0.8131 & 1.4261 & 0.6707 & 3.6 \\
\hline $2010 / 8 / 2313: 55$ & 0.5518 & 0.6825 & 1.5094 & 1.0073 & 11.4 \\
\hline $2010 / 8 / 2513: 40$ & 0.6758 & 0.866 & 1.7356 & 1.1435 & 11.9 \\
\hline
\end{tabular}

\section{EXPERIMENTS}

\section{A. Results from Regressive Analysis}

The Pearson's correlation coefficient is defined as equation (5). Using the aforementioned match-up data, correlation coefficients are evaluated for the different spectral channels of MODIS. Table 3 shows the results. The correlation coefficient 
of $667 \mathrm{~nm}$ wavelength channel is greatest followed by 531, 443, and $412 \mathrm{~nm}$ of wavelength channels as shown in Figure 2.

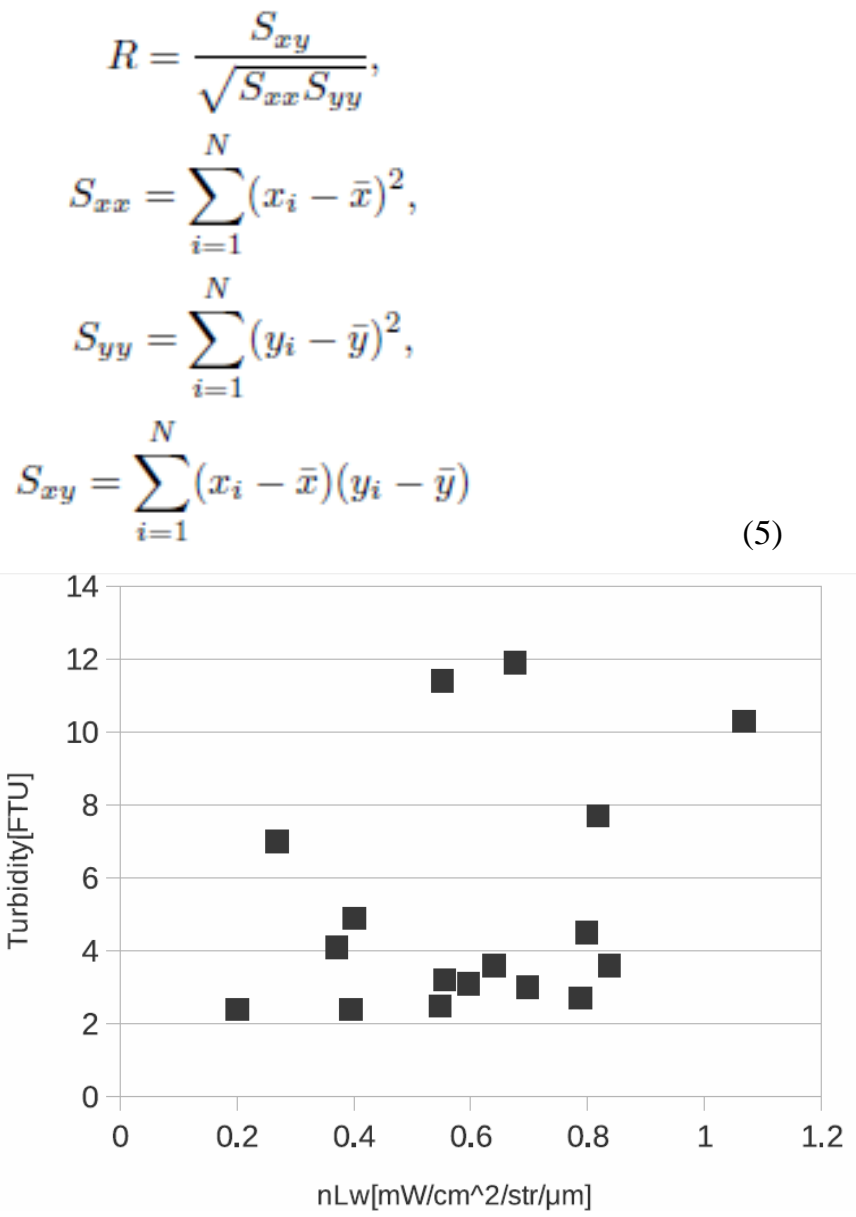

(a) $412 \mathrm{~nm}$

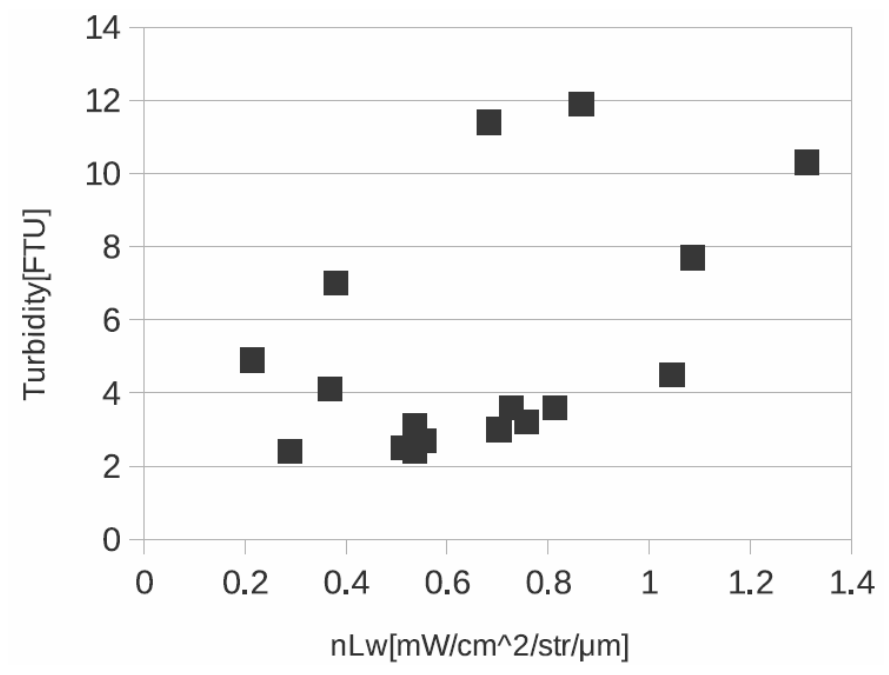

(b) $443 \mathrm{~nm}$

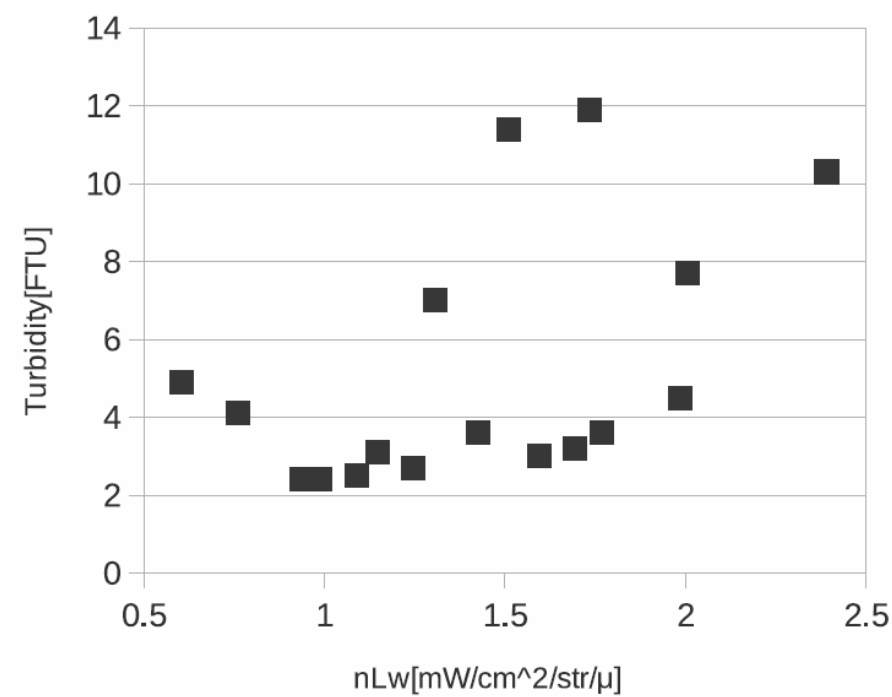

(c) $531 \mathrm{~nm}$

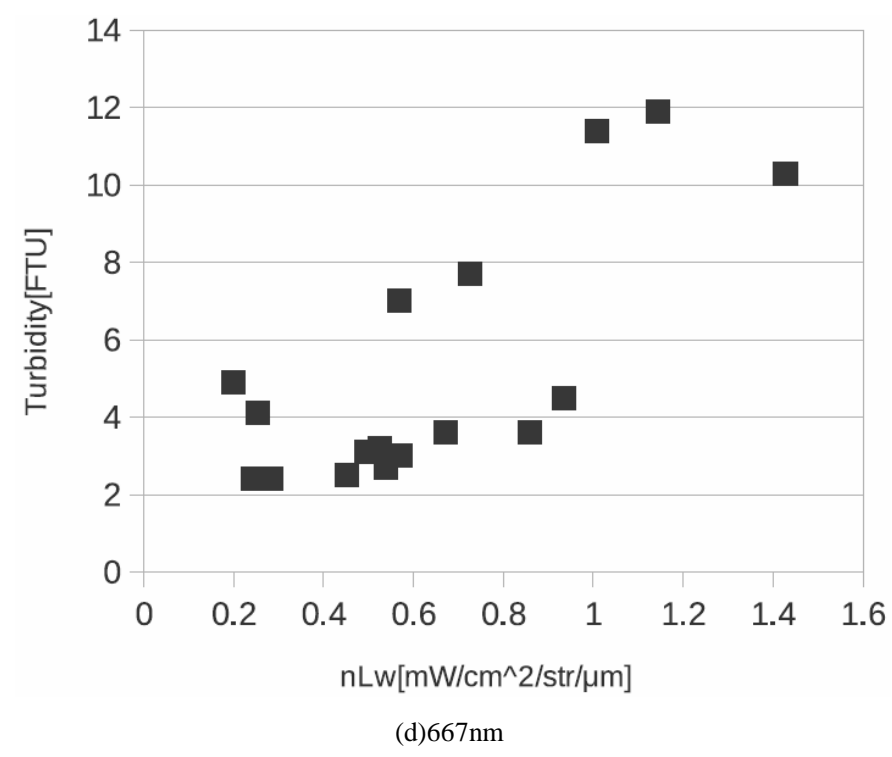

Fig.2. Relations between turbidity and water leaving radiance derived from MODIS

TABLE III. CORRELATION COEFFICIENT FOR EACH WAVELENGTH BAND

\begin{tabular}{|c||c|c|c|c|}
\hline & 412 & 443 & 531 & 667 \\
\hline $\mathrm{R}$ & 0.29882 & 0.47335 & 0.49884 & 0.74805 \\
\hline
\end{tabular}

Therefore, regressive analysis between turbidity and water leaving radiance at $667 \mathrm{~nm}$ is conducted based on equation (1). The result is shown in equation (6).

Turb $^{\prime}=7.0948 *\left[L_{w}(667)\right]_{N}+0.6463$

\section{B. Correlation Coefficient Between Turbidity and MODIS} Based Water Leaving Radiance

Possible reason for this is shown in Figure 3. In accordance with increasing of SS, reflectance at $667 \mathrm{~nm}$ is decreased. 
The variance of the reflectance at $667 \mathrm{~nm}$ is greatest followed by 531, 443, and 412nm of wavelength channels.

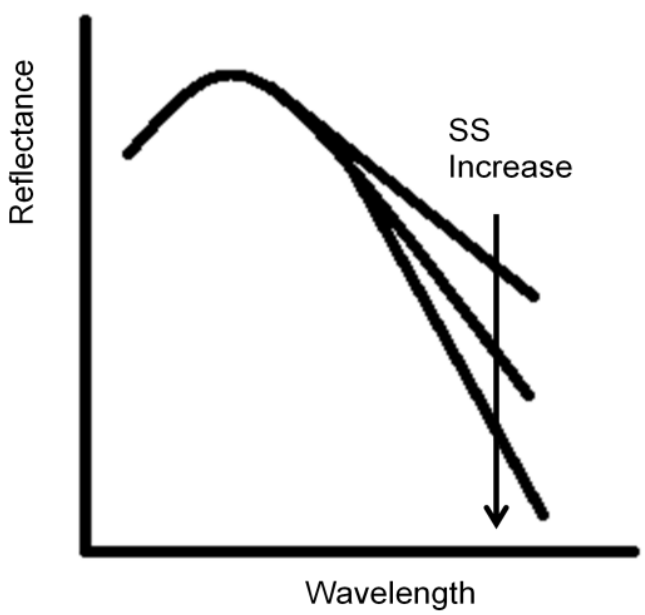

Fig.3. Illustrative view of spectral reflectance for the different suspended solid concentrations.

\section{Ocean Current Velocity}

In the same time as turbidity data is acquired at Saga University Observation Tower, other fundamental observation items are measured including ocean current velocity. In particular, it is known that ocean current velocity is proportional to turbidity. In order to confirm this fact, regressive analysis is made for ocean current velocity. Figure 4 shows the relation between turbidity and logarithmic function of ocean current velocity.

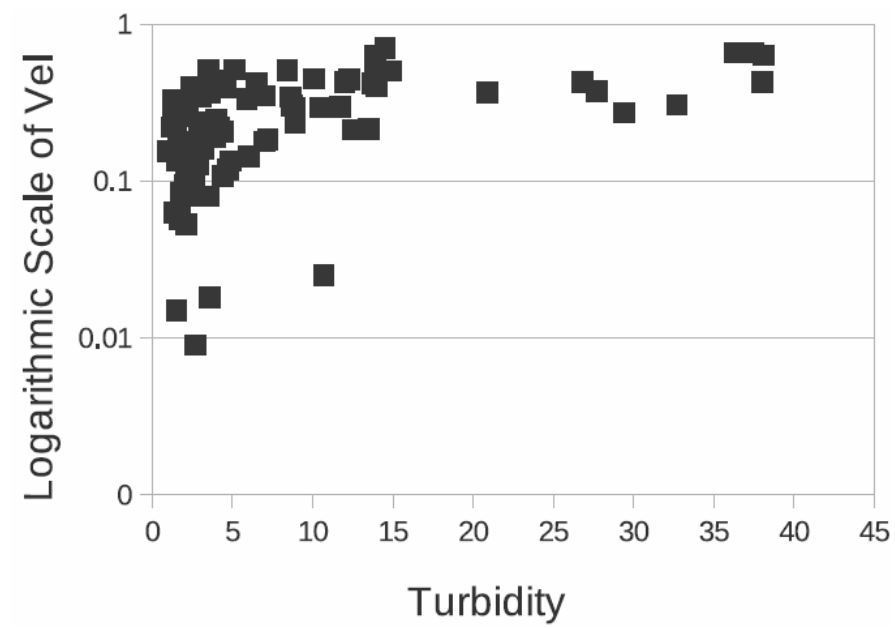

Fig.4. Relation between turbidity and logarithmic function of ocean current velocity

Positive correlation between turbidity and ocean current velocity then is confirmed. From the regressive analysis, the following equation is obtained with Root Mean Square Error: RMSE of 0.1266 .

$$
\text { Vel }^{\prime}=0.109095 * \ln \left(\text { Turb }^{\prime}\right)+0.095643
$$

Thus turbidity and ocean current velocity of the Ariake Sea area can be estimated with the atmospheric corrected MODIS data.

\section{Examples of Estimated turbidity and Ocean Current Velocity}

Using the atmospheric corrected MODIS data of the Ariake Sea area of 2004 and 2006 (which is shown in Table 4), spatiotemporal variations of turbidity and ocean current velocity are estimated. Figure 5 shows the estimated turbidity and ocean current velocity.

TABLE IV. MODIS DATA USED FOR ESTIMATION OF TURBIDITY AND OCEAN CURRENT VELOCITY

\begin{tabular}{|c|c|c|c|}
\hline 2004-fh:Turbidity & 2010-fh:Turbidity & 2004-fh:Velocity & 2010-fh:Velocity \\
\hline T2004030021000 & T2010055020500 & A2004031042500 & T2010026023500 \\
\hline T2004041015000 & T2010098014500 & A2004047042500 & T2010055020500 \\
\hline T2004044022000 & T2010137015000 & A2004049041500 & T2010098014500 \\
\hline T2004046021000 & T2010160015500 & A2004086043000 & T2010137015000 \\
\hline A2004031042500 & A2010017042000 & A2004088042000 & T2010154023500 \\
\hline A2004047042500 & A2010026041000 & A2004091045000 & T2010160015500 \\
\hline A2004100044500 & A2010054043500 & A2004100044500 & A2010017042000 \\
\hline A2004116044500 & A2010093044000 & A2004116044500 & A2010026041000 \\
\hline A2004157044000 & & A2004157044000 & A2010052045000 \\
\hline & & T2004030021000 & A2010054043500 \\
\hline & & T2004041015000 & \\
\hline & & T2004044022000 & \\
\hline & & T2004046021000 & \\
\hline & & T2004096015500 & \\
\hline & & T2004119020500 & \\
\hline
\end{tabular}

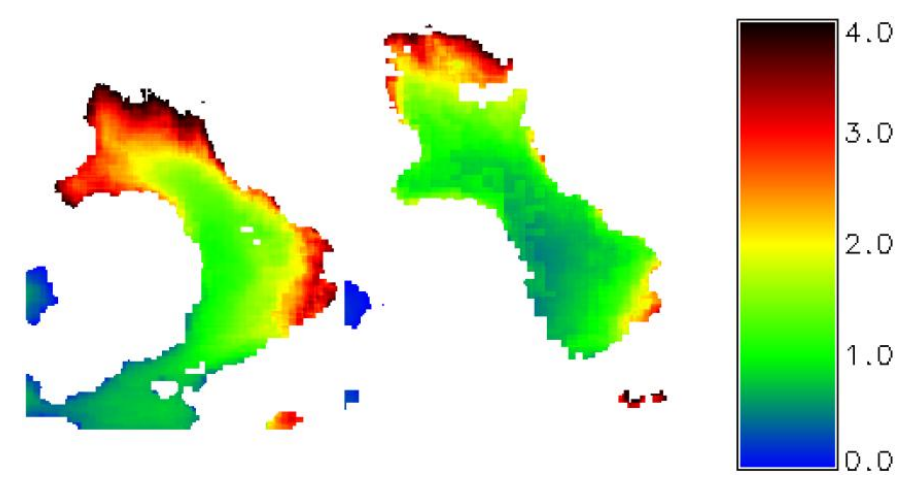

(a)Turbidity in 2004 (b)Turbidity in 2006

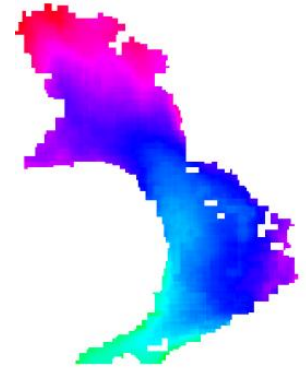

(c) Velocity in 2004
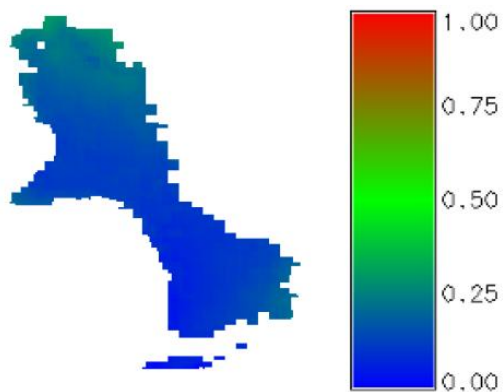

(d) Velocity in 2006
Fig.5. Example of the estimated turbidity and ocean current velocity of the Ariake Sea area in 2004 and 2006

\section{E. Trend Analysis of Turbidity and Ocean Current Velocity}

Trend analysis of turbidity and ocean current velocity, then can be done with the atmospheric corrected MODIS data. Figure 6 shows the result from the trend analysis for 12 years 
starting from 2000 to 2011. Meanwhile, annual mean of turbidity is shown in Figure 7 together with its linear approximated trend in 12 years. From the trend, it is found that the linear approximation function is expressed in equation (8) with $\mathrm{R}$ square value of 0.58 .

$$
f(x)=-0.05 x+2.78
$$

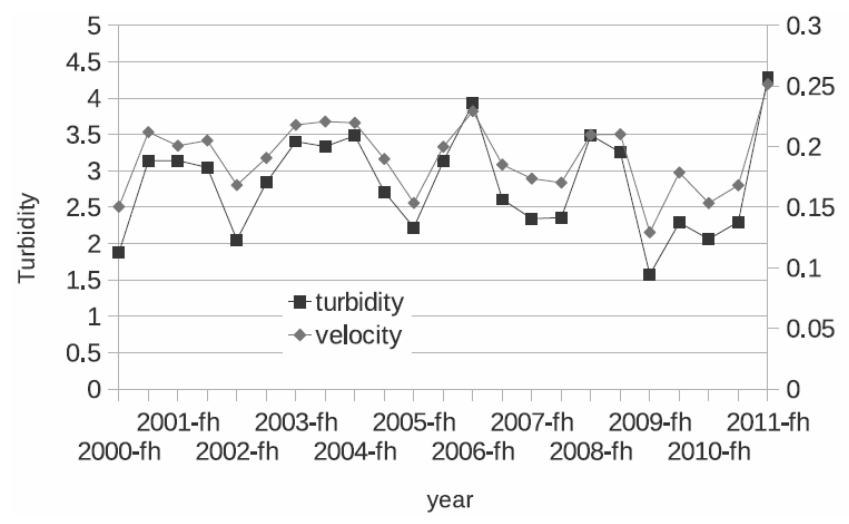

Fig.6. Result from the trend analysis for 12 years starting from 2000 to 2011

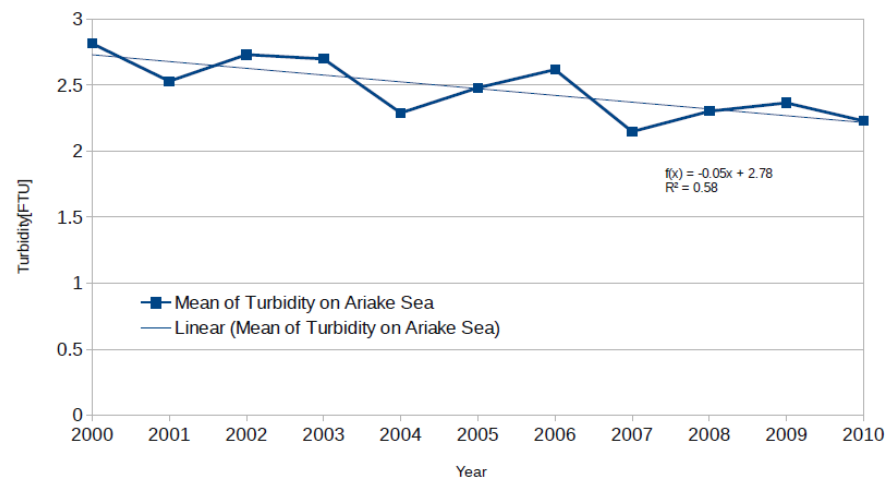

Fig.7. Annual mean of turbidity and its linear approximation function

\section{F. Spatial Variation of Turbidity}

Bi-annual mean of turbidity of the Ariake Sea during from 2000 to 2010 is shown in Figure 8. In particular, turbidity of the Shiranui Sea areas and further southern portion of areas is getting decreases during from 2000 to 2004 , and gradually increased during from 2004 to 2006.

After that, it is getting decreases again during 2006 to 2010 (much severely in 2010 and the after. In other words, transparency of such areas is getting large results in photosynthesis in the Ariake Sea areas is getting much active.

In accordance with increasing of photosynthesis activity, phytoplankton is increases together with zoo plankton results in increasing of red tide occurrences. Also it is recognized that the turbidity of the areas just above the Isahaya Sea areas and northern portion of sea areas is getting decreases. Therefore, it can be said that one of the causes of the increasing red tide occurrence in the Shiranui Sea areas and the Ariake Sea areas must be decreasing of ocean current (decreasing of turbidity).

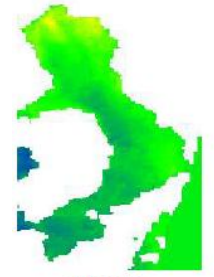

2000

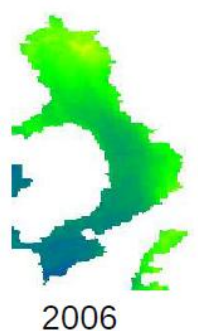

2006

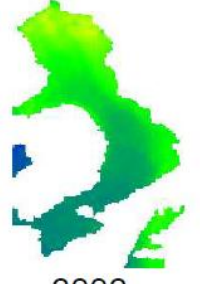

2002

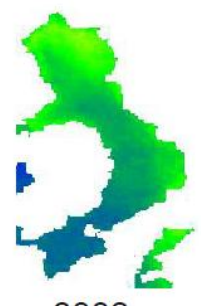

2008

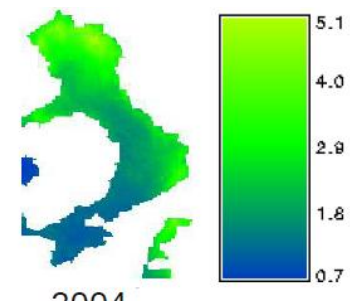

2004

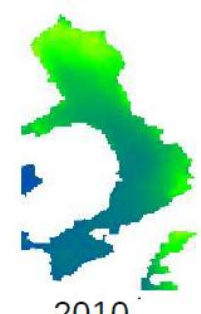

2010
Fig.8. Bi-annual mean of turbidity of the Ariake Sea during from 2000 to 2010

\section{CONCLUSION}

Regression analysis based method for turbidity and ocean current velocity estimation with remote sensing satellite data is proposed. Through regressive analysis with MODIS data and measured data of turbidity and ocean current velocity, regressive equation which allows estimation of turbidity and ocean current velocity is obtained. With the regressive equation as well as long term MODIS data, turbidity and ocean current velocity trends in Ariake Sea area are clarified. It is also confirmed that the negative correlation between ocean current velocity and turbidity

Also it is found that phytoplankton is increases together with zoo plankton results in increasing of red tide occurrences in accordance with increasing of photosynthesis activity. Also it is recognized that the turbidity of the areas just above the Isahaya Sea areas and northern portion of sea areas is getting decreases. Therefore, it can be said that one of the causes of the increasing red tide occurrence in the Shiranui Sea areas and the Ariake Sea areas must be decreasing of ocean current (decreasing of turbidity).

\section{ACKNOWLEDGMENT}

The authors would like to thank Dr. Toshiya Katano of Saga University for his great effort to provide Saga University Observation Tower's data and discussions we have had during this research.

\section{REFERENCES}

[1] S.Yamagata, K. Sakurada, N. Koyama, R. Itoyasma, Long term trend of water quality in Ariake, Yatsushiro Sea, Yusui Report, No.16, 2008.

[2] Y. Shimizu, K.Yamada, Long term transparency raising trend of Ariake Sea, and relation to red tide occurrence, Oceanography in Japan, 17, 337-356, 2008

[3] S.Yamamoto, T.Ozu, T.Shimomai, S.Nonohara, Y.Sakuno, Estimation of turbidity distribution in Lake Shinji, Nakaumi using MODIS data, LANGUNA, 14, 57-68, 2007.

[4] Howard R. Gordon, Kenneth J. Voss,"MODIS Nor-malized 
[5] Waterleaving Radiance Algorithm Theoret-ical Basis Document (MOD18) Version 5", University of Miami, 2004

[6] J. Clerk Maxwell, A Treatise on Electricity and Magnetism, 3rd ed., vol. 2. Oxford: Clarendon, 1892, pp.68-73., 2004.

\section{AUTHORS PROFILE}

Kohei Arai, He received BS, MS and PhD degrees in 1972, 1974 and 1982, respectively. He was with The Institute for Industrial Science, and Technology of the University of Tokyo from 1974 to 1978 also was with National Space Development Agency of Japan (current JAXA) from 1979 to
1990. During from 1985 to 1987 , he was with Canada Centre for Remote Sensing as a Post Doctoral Fellow of National Science and Engineering Research Council of Canada. He was appointed professor at Department of Information Science, Saga University in 1990. He was appointed councilor for the Aeronautics and Space related to the Technology Committee of the Ministry of Science and Technology during from 1998 to 2000. He was also appointed councilor of Saga University from 2002 and 2003 followed by an executive councilor of the Remote Sensing Society of Japan for 2003 to 2005. $\mathrm{He}$ is an adjunct professor of University of Arizona, USA since 1998. He also was appointed vice chairman of the Commission "A" of ICSU/COSPAR in 2008. He wrote 30 books and published 332 journal papers 